\title{
ALCOHOL AND WITHDRAWAL: FROM ANIMAL RESEARCH TO CLINICAL ISSUES
}

Ph. De Wittea, , E. Pintob, M. Ansseau ${ }^{b}$, P. Verbanck ${ }^{c}$

aLaboratoire de Biologie du Comportement, Université catholique de Louvain, Place Croix du Sud, 1-Bte 10, B-1348 Louvain-la-Neuve, Belgium

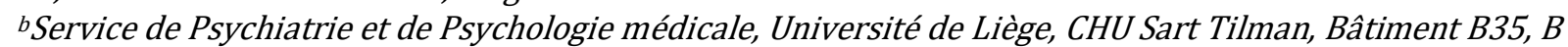
4000 Liège, Belgium

cClinique Alcoologie et Toxicomanies, Université Libre de Bruxelles, CHU Brugmann, Place A. Van Gehuchten 4, B 1020 Brussels, Belgium

KEYWORDS: alcohol, withdrawal, stress, amino acids, dopamine, serotonin, noradrenaline

\section{ABSTRACT}

The withdrawal syndrome in alcohol-dependent patients appears to be a major stressful event whose intensity increases with repetition of detoxifications according to a kindling process. Disturbances in the balance between excitatory and inhibitory neural processes are reflected in a perturbed physical state while disturbances in the balance between positive and negative reinforcements are reflected in a perturbed mood state. Our purpose is to link the different behavioral outcomes occurring during withdrawal with specific biological brain mechanisms from the animal to the human being. Better understanding of the various biological mechanisms underlying withdrawal from alcohol will be the key to design and to apply appropriate pharmaceutical management, together with appropriate therapy aimed at inducing protracted abstinence. 


\section{Dependence and withdrawal}

Withdrawal stands at the core of alcohol dependence. A large body of literature has stated that no real alcohol dependence occurs without withdrawal signs.

Withdrawal signs appear within hours of cessation of alcohol intake. They are associated with a negative mood state including anxiety and tension. Alcohol may thus act as a negative reinforcement, as animals and humans beings will tend to avoid environments and behaviors inducing this negative state. At this stage alcohol intake is able to suppress and may even prevent the occurrence of the physical and mood disturbances. Alcohol and related components will therefore be perceived as highly attractive and will represent a potentially powerful reinforcement. Animals and humans will seek environments and develop behaviors aiming at the intake of alcohol.

These synergic negative and positive effects produced by alcohol give rise to withdrawal and protracted withdrawal, a pivotal role in the way out of alcoholism.

Animal studies may provide useful biological insights for a better understanding of human alcohol withdrawal.

During alcohol dependence, neuroadaptations within the central nervous system (CNS) occur allowing the brain to function regularly while being disturbed by alcohol. Ethanol is not a molecule with a single clear effect on a particular neurotransmitter system but it may affect multiple stages of the neurotransmission cascade of the large majority of neurotransmitters.

Our major goal is not to precisely describe the modifications at the different levels of the neurotransmitters, neuromodulators and neurohormones, but rather to define the occurrence of drinking according to the intensity of the physical signs and the mood state induced by withdrawal. When alcohol intake is arrested, CNS changes are by far the main source of signs and symptoms of adjustment of physical and mood state. Physical state is the reflection of a brain homeostatic balance between excitatory and inhibitory mechanisms while mood state depends on a hedonic balance leading to positive and negative reinforcements.

\section{BRAIN HOMEOSTASIS}

Cessation of chronic alcoholization leads the brain to an overexcited state observed through signs such as tremor and sometimes seizures.

This overexcitement is due to increase in glutamate transmission (a major neuroexcitatory amino acid) combined with an altered GABAA transmission (a major neuroinhibitory pathway). Recent microdialysis studies showed that ethanol withdrawal was associated with increase in glutamate in the striatum [1], the nucleus accumbens (NAC) [2] and hippocampus [3]. Human studies have indicated that excitatory neurotransmitters were elevated in the CSF of alcoholdependent patients [4]. Changes in $\mathrm{GABA}_{A}$ receptors subunits (particularly $\alpha 1-5$ and $\beta 2-3$ ) reduce the inhibitory activity of GABA contributing to hyperexcitability of neurons [5]. Moreover, intermittent withdrawal is also accompanied by an increase in aspartate (a 
neuroexcitatory amino acid) and modification in $\mathrm{GABA}_{\mathrm{A}} \alpha 4$ subunit, probably leading to a 'kindled overexcitation' [6,7].

The neural activity modulated by both excitatory and inhibitory influences are dependent on the influx of calcium into the cells through receptor-operated calcium channels and voltage operating channels. A general adaptive increase in these channels is observed during tolerance and withdrawal leading to generalized neuronal excitability induced by calcium entry $[8,9]$.

Adenosine can also function as an inhibitory modulator of seizure activity. Adenosine A1 receptors are upregulated during ethanol withdrawal and repeated ethanol withdrawals [10]. This likely represents an adaptive response to seizure severity induced by repeated episodes of withdrawal.

Adenosine alters the responding levels of second messengers (like cyclic adenosine monophosphate, protein phosphatase, protein kinase $\mathrm{A}$ and $\mathrm{C}$ ) allowing information to be transmitted more or less effectively to the connected neurons. Blockade of adenosine activity can reduce the occurrence of seizures at the cessation of chronic ethanol intake [11] without affecting ethanol consumption [12].

Alcohol intake is always able to rapidly abolish the negative reinforcement induced by its withdrawal and it would thus appear as a powerful medication against physical perturbations. Other classical neurotransmitters also mediate physical signs of alcohol withdrawal but to a lower extent, since agonists and antagonists of monoamines modify in a limited extend to those physical signs $[13,14]$.

\section{HEDONIC HOMEOSTASIS}

Withdrawal from alcohol leads to a state inducing increase of dysphoria, anxiety, negative emotional state and stress probably because of a decrease in dopamine (DA) release in the NAC. The symptoms can be easily alleviated by alcohol intake. This may be related to an increase of DA activity in the NAC, as observed in rats where self-administered alcohol during withdrawal was able to rapidly reverse the deficit in DA and serotonin in the NAC [15].

DA is the major neurotransmitter released during attracted stimuli (including drugs), particularly in the NAC. Even anticipation of reward (but not punishment) leads to DA release in the NAC [16]. Among various modifications in neurotransmission after alcohol cessation, an increase in acetylcholine (ACHe) was observed in hippocampal microdialysate following the same timing of the deficit in DA accumbal release [17]. In parallel to the putative role of DA in positive reinforcement, ACHe may play a major role in the negative reinforcement [18].

The endogenous opioid system also indirectly activates the mesolimbic dopaminergic system and particularly the opioid receptor may modulate this dopaminergic deficit during alcohol withdrawal [19].

Withdrawal represents a major source of stress and the limbic system will immediately answer by secreting corticotropin-releasing factor (CRF) [20]. The limbic system is a large complex of brain structures regulating emotional processes. It plays a role in the negative reinforcement induced by withdrawal. Direct CRF antagonist injection into limbic areas were able to block anxiogenic-like responses induced by withdrawal [21]. CRF R1 or R2 receptors deficient 
knockout mices present opposite impairments in anxiety-like (estimated by open-field test and light-dark test) and memory disorders. They also show opposite activity profiles during withdrawal signs [22]. CRF R1 receptors are directly activated in alcohol withdrawal and lead to anxiogenic-like responses. The time schedule of the CRF release in the amygdala observed during alcohol withdrawal is long lasting (peak value around $12 \mathrm{~h}$ after onset of withdrawal) as compared to conventional restraint stress (return to baseline CRF after $1 \mathrm{~h}$ ) [21]. CRF in cerebrospinal fluid is also elevated during withdrawal in alcohol patients [23] and protracted abstinence enhances neuronal sensitivity to CRF in rats (estimated by EEG and event-related potentials) 15 weeks after complete withdrawal [24]. This long lasting increase in sensitivity to CRF may induce increased sensitivity to daily environmental stresses and thus may lead to secondary conditioned reinforcement.

During such conditioning, environmental stimuli or internal stimuli associated with withdrawal can act as cues for the appearance or exacerbation of the neurochemical modifications leading to a kindling process.

A common trait emerging when analyzing the neurochemical changes appearing during physical and mood state withdrawal modifications, is that alcohol intake leads to the immediate abolishment of undesirable symptoms. With conditioned secondary reinforcement and the kindling process associated with repeated withdrawals, self-administration of alcohol will progressively increase and will stabilize at a higher level [25].

\section{Alcohol withdrawal syndrome}

The alcohol withdrawal syndrome is a complex set of symptoms occurring in alcohol dependent patients after alcohol cessation. It involves a wide range of brain neurotransmitters implicated in the development of alcohol tolerance and reflects a homeostatic readjustment of the CNS [26]. The signs and symptoms of alcohol withdrawal syndrome have been well described in humans. They can be divided into three sets although many classifications have been made for various purposes [27]. In the first hours following the last alcohol intake, sympathetic hyperactivity is responsible for tachycardia, sweating, tremor, hypertension, anxiety and agitation that usually peak within $24 \mathrm{~h}$. Later on ( 24 - $48 \mathrm{~h}$ after alcohol cessation), epileptic seizures may occur, whereas delirium tremens can be observed from 3 to 7 days after acute abstinence. This third set of symptoms is characterized by auditory and visual hallucinations, confusion and disorientation, clouding of consciousness and pronounced autonomic hyperactivity. It can lead to death from respiratory and cardiovascular collapse [28]. All these symptoms are disabling enough to lead many patients to resume alcohol consumption at the early stages of withdrawal. The severity of alcohol withdrawal syndrome is therefore a major risk factor of early relapse [29]. The understanding of its complex pathophysiology may help finding effective tools in preventing such an event. 


\section{DOPAMINERGIC SYSTEM}

As mentioned above, among the many neurotransmitters involved in alcohol withdrawal, DA seems to play a central role both in tolerance to and withdrawal from alcohol. Alcohol activates the mesolimbic dopamine system by releasing DA in the NAC and it has been hypothesized that subjects with impaired dopaminergic activity may compensate for this deficiency by the use of alcohol and other substances that increase brain DA levels [30,31]. Both neuroendocrine [32] and genetic studies [33] have highlighted the implication of a reduced DAD2 receptor (DRD2) functioning in severe alcohol dependence. Whether this deficiency plays a role in some of the symptoms observed during withdrawal is still controversial, but the hypothesis of a reduced dopaminergic activity in the mesocorticolimbic reward pathway, responsible for negative mood states after alcohol cessation remains attractive [34]. Indeed, it has been shown that alcoholic patients carrying the A1 allele of the DRD2 gene exhibit lower densities of postsynaptic D2receptors [35,36], which may result in low DA neurotransmission. These patients displayed increased depressive symptoms during acute alcohol withdrawal [37]. Poor dopaminergic functioning during the early stages of withdrawal and consecutive depressive symptoms could also be linked to higher recoveries in dopamine transporter (DAT) density in some alcoholic patients shortly after alcohol cessation [38]. It has been shown that this protein, which seems to be decreased during prolonged heavy drinking [39], reuptakes DA into presynaptic terminals and thereby terminates dopaminergic activity in synaptic neurotransmission [40]. This is in accordance with a reported increase of DAT levels in depressed patients [41]. However, opposite fi concerning DA availability and its clinical consequences have been reported. Many reports suggest a DA overactivity during alcohol withdrawal, which may be linked to decreased GABAergic neurotransmission. It has been shown that GABAergic neurons directly inhibit dopaminergic neurons in the substantia nigra [42]. Therefore reduced GABAergic activity, as observed during alcohol withdrawal, leads to enhanced dopaminergic transmission, which could be responsible for more severe withdrawal symptoms [43]. This is in accordance with many studies showing higher concentrations of the DA metabolite homovanillic acid in alcoholics with delirium compared to patients who did not suffer from clouding of consciousness [44]. Furthermore, insufficient clearance of DA in the synaptic cleft leading to hyperdopaminergic states may be related to severe withdrawal symptoms [45], as suggested by the higher risk of seizures or delirium during withdrawal in patients carrying the A9 allele of the DAT-gene [40][46]. The functional consequence of the presence of this allele could indeed induce an alteration in DAT-gene expression [47] resulting in lower DA reuptake.

In summary, dopaminergic neurotransmission may be responsible for various symptoms of the alcohol withdrawal syndrome. Dopaminergic hypoactivity may cause dysphoric features while its overactivity could induce hallucinations. This can be paralleled to the putative pathophysiological mechanisms underlying psychotic symptomatology in which subcortical mesolimbic rewarding DA projections and mesocortical cognitive projections seem to interact in opposite ways, roughly underlying negative symptoms on the one hand, and positive on the other hand [48]. 


\section{SEROTONERGIC SYSTEM}

As for the serotonergic system, it has been demonstrated that serotonin (5-HT) could play a facilitator role on DA release in the NAC $[49,50]$ while ethanol seems to directly stimulate the release of DA and 5-HT [51]. This could lead to a deficiency in the release of these neurotransmitters during ethanol withdrawal. Furthermore, interactions between impaired serotonergic neurotransmission and anxiety and depression have been postulated. As a 5-HT deficiency seems to be involved in alcohol dependence as well as in the maintenance of excessive alcohol consumption [52 - 54], it could be expected to influence the occurrence of mood symptoms in alcoholics, especially during withdrawal. This hypothesis was tested in alcoholdependant rats, suggesting that deficits in accumbal 5-HT release may contribute to the negative affective consequences of alcohol withdrawal and motivate ethanol-seeking behavior [15].

In human, a significant reduction in the availability of 5- HT transporters was found in the raphe nuclei area of recently detoxified alcoholics, which was strongly correlated with increased levels of anxiety and depression during early abstinence [55]. Furthermore, reduced transcriptional efficiency of the serotonin transporter (5HTT) may underlie another set of symptoms during alcohol withdrawal. The frequency of the short allele of the polymorphism coding for 5HTT, responsible for modifications in 5-HT activity [56] was indeed strongly increased in alcoholics who reported seizures or delirium including hallucinations [47].

Finally, it has been postulated that deficiency of brain 5- HT activity in alcoholics may result in a decreased impulse-control over drug taking [57], particularly during alcohol withdrawal. According to Cloninger's typology [58], this may lead to increased craving and anxiety during withdrawal, particularly in type II alcoholics, who are supposed to have low cerebrospinal fluid levels of 5-HT and its metabolite 5-HIAA, as opposed to late-alcoholism-onset-type I subjects [59]. Behavioral differences between type I and type II alcoholics were also observed by George et al. [60] who, after a $m$-chlorophenylpiperazine ( $m$-CPP) challenge test, linked this finding to a hypo-5-HT2C receptor function.

\section{NORADRENERGIC SYSTEM}

Finally, attention should also be focused on another neurotransmitter involved in the pathophysiology of alcohol withdrawal, namely noradrenaline. An important aspect of withdrawal is increased central excitation, which leads to a sympathetic overactivity. Plasma and cerebrospinal fluid levels of noradrenaline are increased because of the overstimulation of noradrenergic neurons by the increased glutamate transmission and the loss of noradrenergic autoinhibition by reduced postsynaptic a2-adrenoreceptor function [61]. Many studies have reported a persistent hypo-a2-adrenoreceptor functioning during and after withdrawal as assessed by a blunted growth hormone (GH) response to clonidine [62 64]. GH response to clonidine is also known to be impaired in endogenous depression $[65,66]$ as well as in panic disorder [67,68]. Impaired a2-adrenoreceptor function might therefore be hypothesized to be responsible for anxiety and depressive symptoms occurring during alcohol withdrawal. However, no evidence for a relationship between dysphoric features and $a 2$-adrenoreceptor subsensitivity has been found to date [69]. Alternatively, the noradrenergic overdrive observed in alcohol withdrawal may solely be implicated in autonomic symptoms 
such as tachycardia, hypertension, tremor and sweating. As mentioned above, alcohol withdrawal reflects altered function of the brain processes involved in the development of tolerance to alcohol. In particular, impaired balance between inhibitory functions and excitatory systems seems to be implicated in the occurrence of some of the symptoms observed during acute withdrawal. On the one hand, chronic alcohol consumption enhances $g$-aminobutyric acid (GABA) inhibitory action, while on the other hand, it blocks some of the brain excitatory systems such as the glutamate $N$-methyl-D-aspartate (NMDA) receptor. The increase in the number of these receptors observed during chronic alcohol intoxication, has been interpreted as an attempt by the brain to compensate for diminished glutamate transmission [26]. Thus, when alcohol is acutely removed, GABA receptors are no longer stimulated while NMDA function is excessive. The latter is also due to the magnesium depletion observed in chronic alcoholism [70]. NMDA overactivity seems, among other pathways, to induce noradrenaline release, and may therefore contribute to the increased sympathetic activity observed during withdrawal. (cf. Table 1)

Table 1. Putative relationships between neurotransmitters disturbances and alcohol withdrawal symptoms

\section{Neurotransmitters Chronic alcohol Withdrawal Withdrawal} symptoms

\begin{tabular}{llll}
$\begin{array}{l}\text { Glutamate } \\
\text { Aspartate }\end{array}$ & $\searrow$ & $\nearrow$ & $\begin{array}{l}\text { Seizures } \\
\text { Sympathetic overdrive } \\
\text { GABA }\end{array}$ \\
Noradrenaline & $\searrow$ & $\searrow$ & $\begin{array}{l}\text { Anxiety } \\
\text { Sympathetic overdrive } \\
\text { Dopamine }\end{array}$ \\
& $\searrow$ & $\searrow$ or $\nearrow$ & $\begin{array}{l}\text { Sympathetic overdrive } \\
\text { Depression or } \\
\text { hallucinations/ } \\
\text { delirium tremens }\end{array}$ \\
& & Anxiety \\
Serotonin & $\nearrow$ or $\searrow$ & $\searrow$ & Depression \\
\hline
\end{tabular}




\section{Alcohol withdrawal syndrome as a stressor}

When managed in a medical setting, the severity of the symptoms and signs of withdrawal in alcohol-dependent patients is usually maximal on the first day of abstinence, and then decreases over a period of $5-7$ days.

In the search for neurobiological markers of the syndrome, it has been shown that acute alcohol withdrawal is associated with hypercortisolaemia [71 - 75] and increase of salivary cortisol levels [76]. The magnitude of cortisol increase was related to the severity of withdrawal symptoms. The mechanism of hypercortisolaemia during alcohol withdrawal remains unclear. It does not appear to be due to hypothalamo-pituitary-adrenal axis hyperactivity since plasma ACTH concentration is decreased at baseline [72] and after injection of corticotrophin-releasing hormone $[77,78]$.

Biochemical studies indicate that increased plasma levels of norepinephrine are associated with certain symptoms of alcohol withdrawal like blood pressure and heart rate response to standing [79] and that the severity of the withdrawal syndrome correlates positively with the amount of released norepinephrine [80,81].

In addition to medullo-adrenal and sympathetic hyperactivity, there are also indications of central adrenergic hypersecretion during alcohol withdrawal. High concentrations of norepinephrine and its major metabolite 3-methoxy-4-hydroxyphenylglycol (MOPEG) have been reported in cerebrospinal fluid in alcohol withdrawn patients $[82,83]$. In the beginning of the withdrawal manifestations, there is a positive correlation between MOPEG levels and sleeping problems, tremors, restlessness, visual hallucinations and elevated muscle tension [84].

These converging observations that alcohol withdrawal syndrome is a powerful stressor could be of major importance for the understanding of the development of addiction. It has become clear that administration of addictive drugs to laboratory rats can cause time-dependent sensitization that is probably a function of their nonspecific, stressful nature [85]. This is underlined by the fact that there is cross-sensitization between a stress challenge after previous drug administration [86] and a drug challenge after a previous stressful experience [87]. Repeated intracerebroventricular administration of CRF has similar sensitizing effects on later responsivity to amphetamine [88]. Stressful experiences in humans can result in a spectrum of long-term changes in behavioral, autonomic and hormonal responsivity. An extreme form of such alterations is found in patients with post-traumatic stress disorder. A number of animal models has been developed in which intense stressful experiences (such as shocks or social confrontations) result in long-term altered responsivity of behavioral, autonomic and hormonal responses to aversive challenges [89].

Daily exposure to emotional stress enhances the initiation of self-administration of morphine and cocaine, and ventral tegmental intracranial electrical self-stimulation in rats $[90,91]$. Moreover, social defeat directly followed by threat for four consecutive days increases the amount of cocaine self-administration and defeated rats acquire cocaine self-administration in approximately half the time of non-defeated rats [92,93]. These studies suggest that certain types of stress can enhance the addictive properties of drugs, possibly by enhancing the 
sensitivity of the mesocorticolimbic dopaminergic system to these substances. Conversely, druginduced sensitization of the mesocorticolimbic DA system may underlie increased responsiveness to stress.

Therefore, we hypothesize that drug withdrawal syndrome and especially alcohol withdrawal syndrome could be one important factor contributing to the progressive reinforcement of drinking through the progressive sensitization of the brain reward system by stress hormones. This could also be responsible for the higher risk to develop dependence to other drugs in alcoholics.

Such a sensitization to alcohol withdrawal is in accordance with the kindling hypothesis of alcohol withdrawal stated by Ballenger and Post [94]. This hypothesis has recently gained considerable support. Indeed, clinical studies have demonstrated a positive relationship between the number of previous withdrawal reactions and the risk of developing seizures during oncoming withdrawal reactions [95,96, Verbanck et al., unpublished].

These findings are in agreement with animal studies showing increased withdrawal behavior during repeated episodes of alcohol intoxication and withdrawal [97 - 99]. This process can be prevented by blocking the early withdrawal reactions with phenobarbital or diazepam $[100,101]$, even if diazepam was reported to be unable to prevent the occurrence of seizures [102].

\section{Alcohol withdrawal as a neurotoxic event}

Acute effects of ethanol disrupt glutamatergic neurotransmission by reducing the sensitivity of the NMDA receptor [103]. Prolonged inhibition of NMDA receptors by ethanol induces their upregulation. When chronic alcohol consumption ceased, the upregulation combined with an increased release of excitatory amino acids can result in acute excitotoxicity [4]. Neurobiological effects of alcohol on the brain, such as intoxication, withdrawal symptoms and WernickeKorsakoff syndrome can be understood as consequences of effects of ethanol on the glutamatergic system.

Specifically, it was demonstrated that ethanol withdrawal is associated with increased extracellular glutamate [1]. This increase in release of glutamate could have major long-term consequences for the alcoholic patient. There is evidence of specific alcohol-associated frontal lobe injury [104]. While alcohol-induced oxidative stress may cause global brain impairment, the frontal lobes can be specifically injured by glutamate-mediated excitotoxicity because frontal lobes are particularly rich in excitatory amino acid pathways [105]. Using neuropsychological and radioisotopical methods, we demonstrated recently that frontal lobe hypometabolism in detoxified alcoholics induces specifically a major impairment of executive functions [106,107]. We also demonstrated that this impairment of executive functions (decision-making, flexibility, double-task) is a major clinical issue because it contributes dramatically to the risk of short-term relapse after detoxification [108].

The withdrawal syndrome in alcohol-dependent patients appears to be a major stressful event whose intensity increases with repetition of detoxifications according to a kindling process. These phenomena could be at least partly responsible for a progressive increase of the 
reinforcing power of addictive drugs including alcohol, and for brain damage through an excitotoxic mechanism due to an increasing release of excitatory amino acids during withdrawal. Progressive neurotoxic lesions due to excitotoxicity in the frontal lobe could be a major consequence of repeated alcohol withdrawal, with major neuropsychological deficits negatively influencing the outcome after detoxification.

Hippocampus, another neural structure rich in excitatory amino acids projections, also appears to be particularly sensitive to the neurotoxic effects ethanol administration [109,110], especially after intermittent exposure $[111,112]$. This was demonstrated to result in memory impairments in rats [113]. Hippocampus lesions seem to be due to both excitoxicity [114,115] and glucocorticoids [116 - 120]. A more recent drug, acamprosate, appears to have promising neuroprotective properties against the consequences of multiple withdrawals in animal models [121].

\section{Acknowledgements}

This work was supported by the 'Fonds de la Recherche Scientifique et Médicale' (2001 - 2002). 


\section{References}

[1] Rossetti ZL, Carboni S. Ethanol withdrawal is associated with increased extracellular glutamate in the rat striatum. Eur J Pharmacol 1995;283:177-83.

[2] Dahchour A, Quertemont E, De Witte Ph. Taurine increases in the nucleus accumbens microdialysate after acute ethanol administration to naïve and chronically alcoholised rats. Brain Res 1996;735:9-19.

[3] Dahchour A, De Witte Ph, Bolo N, Nédélec JF, Durbin P, Macher JP. Central effect of acamprosate. Part 1. Acamprosate blocks the glutamate increase in the nucleus accumbens microdialysate during ethanol withdrawn rats. Psychiat Res Neuroimag 1998;82:107-14.

[4] Tsai GC, Coyle JT. The role of glutamatergic neurotransmission in the pathophysiology of alcoholism. Annu Rev Med 1998;49:173-84.

[5] Devaud LL, Fritschy JM, Sieghart W, Morrow AL. Bidirectional alterations of GABAA receptor sub-unit peptide levels in rat cortex during chronic ethanol consumption and withdrawal. J Neurochem 1997;69(1):126-30.

[6] Dahchour A, De Witte Ph. Amino acid transmitter systems in substance-related disorders. In: D'haenen $\mathrm{H}$, den Boer JA, Westenberg H, Willner P, editors. Textbook of biological psychiatry. New York: Wiley; 2002. p. 415-24.

[7] Mahmoudi M, Kang MH, Tillakaratne N, Tobin AJ, Olsen RW. Chronic intermittent ethanol treatment in rats increases GABAA receptor alpha 4-subunit expression: possible relevance to alcohol dependence. J Neurochem 1997;68:2485-92.

[8] Samson HH, Harris RA. Neurobiology of alcohol abuse. Trends Pharmacol Sci 1992;13(5):206-11.

[9] Littleton J, Little H. Current concepts of ethanol dependence. Addiction 1994;89(11):1397-412.

[10] Jarvis MF, Becker HC. Single and repeated episodes of ethanol withdrawal increase adenosine A(1), but not $\mathrm{A}(2 \mathrm{~A})$, receptor density in mouse brain. Brain Res 1998;786(1-2):80-8.

[11] El Yacoubi M, Ledent C, Parmentier M, Daoust M, Costentin J, Vaugeois JM. Absence of the adenosine $\mathrm{A}(2 \mathrm{~A})$ receptor or its chronic blockade decrease ethanol withdrawal-induced seizures in mice. Neuropharmacology 2001;40(3):424-32.

[12] Gatch MB, Wallis CJ, Lal H. The effects of adenosine ligands R-PIA and CPT on ethanol withdrawal. Alcohol 1999;19(1):9-14.

[13] Uzbay IT, Akarsu ES, Kayaalp SO. Effects of bromocriptine and haloperidol on ethanol withdrawal syndrome in rats. Pharmacol Biochem Behav 1994;49(4):969-74.

[14] Meert TF, Huysmans H. Repeated characterization of alcohol-withdrawal reactions in rats chronically exposed to an alcohol liquid diet. Progr Neuro-Psychopha 1994;(5):947-60.

[15] Weiss F, Parsons LH, Schulteis G, Hyytiä P, Lorang MT, Bloom FE, Koob GF. Ethanol selfadministration restores withdrawal-associated deficiencies in accumbal dopamine and 5hydroxytryptamine release in dependant rats. J Neurosci 1996;16:3474-85.

[16] Knutson B, Adams CM, Fong GW, Hommer D. Anticipation of increasing monetary reward selectively recruits nucleus accumbens. J Neurosci 2001;21(16):RC159. 
[17] Imperato A, Dazzi L, Carta G, Colombo G, Biggio G. Rapid increase in basal acetylcholine release in the hippocampus of freely moving rats induced by withdrawal from long-term ethanol intoxication. Brain Res 1998;784(1-2):347-50.

[18] Rada P, Hoebel B. Aversive hypothalamic stimulation releases acetylcholine in the nucleus accumbens, and stimulation-escape deceases it. Brain Res 2001;888:60-5.

[19] Smolka M, Sanders T, Schmidt L, Samochowiec J, Rommelspacher H, Gscheidel Wendel B, Hoehe M. Mu-opioid receptor variants and dopaminergic sensitivity in alcohol withdrawal. Psychoneuroendocrinology 1999;24:629-38.

[20] Merlo-Pich E, Lorang M, Yeganeh M, Rodriguez De Fonseca F, Raber J, Koob GF, Weiss F. Increase of extracellular corticotropin-releasing factor-like immunoreactivity levels in the amygdala of awake rats during restraint stress and ethanol withdrawal as measured by microdialysis. J Neurosci 1995;15:543947.

[21] Rassnick S, Heinrichs SG, Britton KT, Koob GF. Microinjection of corticotropin-releasing factor antagonist into the central nucleus of the amygdala reverses anxiogenic-like effects of ethanol withdrawal. Brain Res 1993;605(1):25-32.

[22] Timpl P, Spanagel R, Sillaber I, Kresse A, Reul JM, Stalla GK, Blanquet V, Steckler T, Holsboer F, Wurst $\mathrm{W}$. Impaired stress response and reduced anxiety in mice lacking a functional corticotropin-releasing hormone receptor 1. Nat Genet 1998;19(2):162-6.

[23] Adinoff B, Anton R, Linnoila M, Guidotti A, Nemeroff CB, Bissette G. Cerebrospinal fluid concentrations of corticotropin-releasing hormone (CRH) and diazepam-binding inhibitor (DBI) during alcohol withdrawal and abstinence. Neuropsychopharmacology 1996;15:288-95.

[24] Slawecki CJ, Somes C, Ehlers CL. Effects of chronic ethanol exposure on neurophysiological responses to corticotropin-releasing factor and neuropeptide Y. Alcohol Alcohol 1999;34(3):289-99.

[25] Roberts AJ, Cole M, Koob GF. Intra-amygdala muscimol decreases operant ethanol self-administration in dependent rats. Alcohol Clin Exp Res 1996;20(7):1289-98.

[26] Nutt D. Alcohol and the brain. Pharmacological insights for psychiatrists. Br J Psychiat 1999;175:1149.

[27] Hall W, Zabor D. The alcohol withdrawal syndrome. Nature 1997;349:1897-900.

[28] Shiloh R, Nutt D, Weizman A. London: Atlas of Psychiatric Pharmacotherapy. Martin Dunitz; 1999

[29] Wise RA. The neurobiology of craving: Implications for the understanding and treatment of addiction. J Abnorm Psychol 1988;97:118-32.

[30] Koob GF, Roberts AJ, Schulteis G, Parsons LH, Heyser CJ, Hyytiä P, Merlo-Pich E, Weiss F. Neurocircuitry targets in ethanol reward and dependence. Alcohol Clin Exp Res 1998;22:3-9.

[31] Nestler EJ, Aghajanian JK. Molecular and cellular basis of addiction. Science 1997;278:58-63.

[32] Schmidt LG, Dettling M, Graef KJ, Heinz A, Kuhn S, Podschus J, Rommelspacher H. Reduced dopaminergic function in alcoholics is related to severe dependance. Biol Psychiatry 1996;39(3):193-8.

[33] Noble EP. Addiction and its reward process through polymorphisms of the D2 dopamine receptor gene: a review. Eur Psychiat 2000;15:79-89.

[34] Roy A, De Jong J, Lamparski D, George T, Linnoila M. Depression among alcoholics. Arch Gen Psychiat 1991;48:428-32. 
[35] Jönsson EG, Nothen MM, Grunhage F, Farde L, Nakashima Y, Propping P, Sedvall GC. Polymorphisms in the dopamine D2 receptor gene and their relationships to striatal dopamine receptor density of healthy volunteers. Mol Psychiat 1999;4:290-6.

[36] Pohjalainen T, Rinne JO, Nagren K, Lehikoinen P, Anttila K, Syvälahti E, Hietala J. The A1 allele of the human D2 dopamine receptor gene predicts low D2 receptor availability in healthy volunteers. Mol Psychiat 1998;3:256-60.

[37] Laine TJ, Ahonen A, Räsänen P, Pohjalainen T, Tihonen J, Hietala J. The A1 allele of the D2 dopamine receptor gene is associated with high dopamine transporter density in detoxified alcoholics. Alcohol Alcohol 2001;3:262-5.

[38] Laine TJ, Ahonen A, Räsänen P, Tihonen J. Dopamine transporter availability and depressive symptoms during alcohol withdrawal. Psychiat Res-Neuroimag 1999;90:153-7.

[39] Laine TJ, Ahonen A, Torniainen P, Heikkila J, Pyhtinen J, Räsänen P, Niemela O, Hillbom M. Dopamine transporters increase in human brain after alcohol withdrawal. Mol Psychiat 1999;4:189-91.

[40] Sander T, Harms H, Podschus J, Finckh U, Nickel B, Rolfs A, Rommelspacher H, Schmidt LG. Allelic association of a dopamine transporter gene polymorphism in alcohol dependence with withdrawal seizures or delirium. Biol Psychiat 1997;41:299-304.

[41] Laasonen-Balk T, Kuikka J, Viinamäki H, Husso-Saastamoinen M, Lehtonen J, Tihonen J. Striatal dopamine transporter density in major depression. Psychopharmacology 1999;144:282-5.

[42] Glue P, Nutt D. Overexcitement and disinhibition. Dynamic neurotransmitter interactions in alcohol withdrawal. Br J Psychiat 1990;157:491-9.

[43] Heinz A, Schmidt K, Sällström-Baum S, Kuhn S, Dufeu P, Schmidt LG, Rommelspacher H. Influence of dopaminergic transmission on severity of withdrawal syndrome in alcoholism. J Stud Alcohol 1996;57:471-4.

[44] Sano H, Suzuki Y, Ohara K, Yazaki R, Ishigaki T, Yokoyama T, Ohara K. Circadian variation in plasma homovanillic acid level during and after alcohol withdrawal in alcoholic patients. Alcohol Clin Exp Res 1992;16:1047-51.

[45] Clements JD. Transmitter timecourse in the synaptic cleft: its role in central synaptic function. Trends Neurosci 1996;19:163-71.

[46] Schmidt LG, Harms H, Kuhn S, Rommelspacher H, Sander T. Modification of alcohol withdrawal by the A9 allele of the dopamine transporter gene. Am J Psychiat 1998;155:474-8.

[47] Schmidt LG, Sander T. Genetics of alcohol withdrawal. Eur Psychiat 2000;15:135-9.

[48] Svensson TH. Dysfunctional brain dopamine systems induced by psychotomimetic NMDA-receptor antagonists and the effects of antipsychotic drugs. Brain Res Rev 2000;31:320-9.

[49] Parsons LH, Justice JrJB. Extracellular concentration and in vivo recovery of DA in the nucleus accumbens using microdialysis. J Neurochem 1992;58:212-8.

[50] Yoshimoto K, McBride WJ. Regulation of nucleus accumbens dopamine release by the dorsal raphe nucleus in the rat. Neurochem Res 1992;17:401-7.

[51] Imperato A, Di Chiara G. Preferential stimulation of dopamine release in the nucleus accumbens of freely moving rats by ethanol. J Pharmacol Exp Ther 1986;239:219-28.

[52] Ballenger J, Goodwin F, Major L, Brown G. Alcohol and central serotonin metabolism in man. Arch Gen Psychiat 1979;36:224-7. 
[53] Mc Bride WJ, Murphy JM, Yoshimoto K, Lumeng L, Li TK. Serotonin mechanisms in alcohol drinking behaviors. Drug Dev Res 1993;30:170-7.

[54] Tollefson GD. Serotonin and alcohol: interrelationships. Psychopathology 1989;22(S1):37-48.

[55] Heinz A, Ragan P, Jones DW, Hommer D, Williams W, Knable MB, Gorey JG, Doty L, Geyer G, Lee KS, Coppola R, Weinberger DR, Linnoila M. Reduced central serotonin transporters in alcoholism. Am J Psychiat 1998;155:1544-9.

[56] Hammouni S, Payen A, Favre JD, Balmes JL, Be'nard JY, Husson M, Ferrand JP, Martin JP, Daoust M. Does the short variant of the serotonin transporter linked polymorphic region constitute a marker for alcohol dependence? Alcohol 1999;2:107-12.

[57] Ciccocioppo R. The role of serotonin in craving: from basic research to human studies. Alcohol Alcohol 1999;34:244-53.

[58] Cloninger CR. Neurogenetic adaptive mechanisms in alcoholism. Science 1987;236:410-6.

[59] Fils-Aime M-L, Eckhardt J, George DT, Brown GL, Mefford I, Linnoila M. Early-onset alcoholics have lower cerebrospinal fluid 5- hydroxy-indoleacetic acid levels than late-onset alcoholics. Arch Gen Psychiat 1996;53:211-6.

[60] George DT, Benkelfat C, Rawlings RR, Eckhardt MJ, Phillips MJ, Nutt DJ, Wynne D, Murphy DL, Linnoila M. Behavioral and neuroendocrine responses to m-chlorophenylpiperazine in subtypes of alcoholics and in comparison subjects. Am J Psychiat 1997;154:81-7.

[61] Nutt D, Glue P, Molyneux S, Clark C. Alpha-2-adrenoreceptor activity in alcohol withdrawal: a pilot study of the effects of i.v. clonidine in alcoholics and normals. Alcohol Clin Exp Res 1998;12:14-18.

[62] Balldin J, Berggren U, Engel J, Lindstedt G, Sundkler A, Walinder J. Alpha-2-adrenoreceptor sensitivity in early alcohol withdrawal. Biol Psychiat 1992;31:712-9.

[63] Glue P, Sellman JD, Nicholls MG, Abbott R, Joyce PR, Nutt D. Studies of alpha-2-adrenoreceptor function in abstinent alcoholics. Br J Addict 1989;84:97-102.

[64] Müller N, Hoehe M, Klein HE, Nieberle G, Kapfhammer HP, May F, Müller OA, Fichter M. Endocrinological studies in alcoholics during withdrawal and after abstinence. Psychoneuroendocrinology 1989;14:113-23.

[65] Ansseau M, von Frenckel R, Cerfontaine JL, Papart P, Franck G, Timsit-Berthier M, et al. Blunted response of growth hormone to clonidine and apomorphine in endogenous depression. Br J Psychiat 1988;153:65-71.

[66] Valdivieso S, Duval F, Mokrani MC, Schaltenbrand N, Castro JO, Crocq MA, Macher JP. Growth hormone response to clonidine and the cortisol response to dexamethasone in depressive patients. Psychiat Res 1996;60:23-32.

[67] Charney DS, Heninger GR. Abnormal regulation of noradrenergic function in panic disorders: effects of clonidine in healthy subjects and patients with agoraphobia and panic disorder. Arch Gen Psychiat 1986;43:1052-4.

[68] Uhde TW, Vittone BJ, Siever LJ, Kaye WH, Post RM. Blunted growth hormone response to clonidine in panic disorder patients. Biol Psychiat 1986;21:1077-81.

[69] Fahlke C, Berggren U, Lundborg C, Balldin J. Psychopathology in alcohol withdrawal: relationship to alpha-2 adrenoreceptor function. Alcohol Alcohol 1999;5:750-9.

[70] Flink EB. Magnesium deficiency in alcoholism. Alcohol Clin Exp Res 1986;10:590-4. 
[71] Bannan LT, Potter JF, Beevers DG, Saunders JB, Walters JR, Ingram MC. Effects of alcohol withdrawal on blood pressure, plasma renin activity, aldosterone, cortisol and dopamine beta-hydroxylase. Clin Sci 1984;66:659-63.

[72] Esel E, Sofuoglu S, Aslan SS, Kula M, Yabanogly I, Turan MT. Plasma levels of beta-endorphin, adrenocorticorticotropic hormone and cortisol during early and late alcohol withdrawal. Alcohol Alcohol 2001;36:572-6.

[73] Heinz A, Rommelspacher H, Graf KJ, Kurten I, Otto M, Baumgartner A. Hypothalamic-pituitarygonadal axis, prolactin, and cortisol in alcoholics during withdrawal and after three weeks of abstinence: comparison with heathy control subjects. Psychiatry Res 1995;56:81-95.

[74] Mendelson JH, Stein S. Serum cortisol levels in alcoholic and nonalcoholic subjects during experimentally induced ethanol intoxication. Psychosom Med 1966;28:616-26.

[75] Risher-Flowers D, Adinoff B, Ravitz B, Bone GH, Martin PR, Nutt D, Linnoila M. Circadian rythms of cortisol during alcohol withdrawal. Adv Alcohol Subst Abuse 1988;7:37-41.

[76] Keedwell PA, Poon L, Papadopoulos AS, Marshall EJ, Checkley SA. Salivary cortisol measurements during a medically assisted alcohol withdrawal. Addict Biol 2001;6:247-57.

[77] Hundt W, Zimmermann U, Pottig M, Spring K, Holsboer F. The combined dexamethasonesuppression/CRH-stimulation test in alcoholics during and after acute withdrawal. Alcohol Clin Exp Res 2001;25:687-91.

[78] Von Bardeleben U, Heuser I, Holsboer F. Human CRH stimulation response during acute withdrawal and after medium-term abstention form alcohol abuse. Psychoneuroendocrinology 1989;14:441-9.

[79] Eisenhofer G, Whiteside EA, Johnson RH. Plasma catecholamine responses to change of posture in alcoholics during withdrawal and after continued abstinence from alcohol. Clin Sci 1985;68:71-8.

[80] Linnoila M, Mefford I, Nutt D, Adinoff B. NIH conference: Alcohol withdrawal and noradrenergic function. Ann Intern Med 1987;107:875-89.

[81] Smith AJ, Brent PJ, Henry DA, Foy A. Plasma noradrenaline, platelet alpha 2-adrenoceptors and functional scores during ethanol withdrawal. Alcohol Clin Exp Res 1990;14:497-502.

[82] Hawley RJ, Major LF, Schulman EA, Lake CR. CSF levels of norepinephrine during alcohol withdrawal. Arch Neurol 1981;38:289-92.

[83] Hawley RJ, Nemeroff CB, Bissette G, Guidotti A, Rawlings R, Linnoila M. Neurochemical correlates of sympathetic activation during severe alcohol withdrawal. Alcohol Clin Exp Res 1994;18:1312-6.

[84] Borg S, Czarnecka A, Kvande H, Mossberg D, Sedvall G. Clinical conditions and concentrations of MOPEG in the cerebrospinal fluid and urine of male alcoholic patients during withdrawal. Alcohol Clin Exp Res 1983;7:411-5.

[85] Sorg BA, Kalivas PW. Effects of cocaine and footshock stress on extracellular dopamine levels in the ventral striatum. Brain Res 1991;559:29-36.

[86] Hamamura T, Ichimaru Y, Fibiger HC. Amphetamine sensitization enhances regional c-fos expression produced by conditioned fear. Neuroscience 1997;76:1097-103.

[87] Diaz-Otanez CS, Del Rosario Capriles N, Cancela LM. D1 and D2 dopamine and opiate receptors are involved in restraint stress-induced sensitization to the psychostimulant effects of amphetamine. Pharmacol Biochem Behav 1997;58:9-14. 
[88] Cador M, Cole BJ, Koob GF, Stinus L, Le Moal M. Central administration of corticotropin-releasing factor induces long-term sensitization to D-amphetamine. Brain Res 1993;606:181-6.

[89] Stam R, Bruijnzeel AW, Wiegant VM. Long-lasting stress sensitisation. Eur J Pharmacol 2000;405:217-24.

[90] Ramsey NF, Van Ree JM. Emotional but not physical stress enhances intravenous cocaine selfadministration in drug-naive rats. Brain Res 1993;608(2):216-22.

[91] Kuzmin A, Semenova S, Zvartea EE, Van Ree JM. Enhancement of morphine self-administration in drug naive inbred strains of mice by acute emotional stress. Eur Neuropsychopharm 1996;6:63-8.

[92] Haney M, Maccari S, Le Moal M, Simon H, Piazza PV. Social stress increases the acquisition of cocaine self-administration in male and female rats. Brain Res 1995;698:46-52.

[93] Tidey JW, Miczek KA. Acquisition of cocaine self-administration after social stress: role of accumbens dopamine. Psychopharmacology 1997;130(3):203 - 12.

[94] Ballenger JC, Post RM. Kindling as a model for alcohol withdrawal syndromes. Br J Psychiat 1978;133:1-14.

[95] Booth BM, Blow FC. The kindling hypothesis: further evidence from a US National Study on alcoholic men. Alcohol Alcohol 1993;28:593-8.

[96] Worner TM. Relative kindling effect of readmissions in alcoholics. Alcohol Alcohol 1996;31:375-80.

[97] Clemmesen L, Hemmingsen R. Physical dependence on ethanol during multiple intoxication and withdrawal episodes in the rat: evidence of a potentiation. Acta Pharmacol Tox 1984;55:345-50.

[98] Becker HC, Hale RL. Repeated episodes of ethanol wtihdrawal potentiate the severity of subsequent withdrawal seizures: an animal model of alcohol withdrawal 'kindling'. Alcohol Clin Exp Res 1993;17:948.

[99] Becker HC, Diaz-Granadoz JL, Hale RL. Exacerbation of ethanol withdrawal seizures in mice with a history of multiple withdrawal experience. Pharmacol Biochem Behav 1997;57:179-83.

[100] Ulrichsen J, Clemmesen L, Hemmingsen R. Convulsive behaviour during alcohol dependence: discrimination between the role of intoxication and withdrawal. Psychopharmacology 1992;107:97-102.

[101] Ulrichsen J, Bech B, Allerup P, Hemmingsen R. Diazepam prevents progression of kindled alcohol withdrawal behaviour. Psychopharmacology 1995;121:451-60.

[102] Mhatre MC, McKenzie SE, Gonzalez LP. Diazepam during prior ethanol withdrawals does not alter seizure susceptibility during a subsequent withdrawal. Pharmacol Biochem Behav 2001;68:339-46.

[103] Lovinger DM. Excitotoxicity and alcohol-related brain damage. Alcohol Clin Exp Res 1993;17:19-27.

[104] Tsai G, Gastfriend DR, Coyle JT. The glutamatergic basis of human alcoholism. Am J Psychiat 1995;152:332-40.

[105] Kril JJ, Halliday GM, Svoboda MD, Cartwright H. The cerebral cortex is damaged in chronic alcoholics. Neuroscience 1997;79:983-98.

[106] Schweinburg BC, Taylor MJ, Alhassoon OM, Videen JS, Brown-Patterson TL, Berger F, Grant I. Chemical pathology in brain white matter of recently detoxified alcoholics: a $1 \mathrm{~h}$ magnetic resonance spectroscopy investigation of alcohol-associated frontal lobe injury. Alcohol Clin Exp Res 2001;25:924-34.

[107] Noël X, Paternot J, Van der Linden M, Sferrazza R, De Mol J, Pelc I, Verbanck P. Correlation between inhibition, working memory and delimited frontal areas blood flow measured by $99 \mathrm{mTc}$-bicisate SPECT in alcohol-dependent patients. Alcohol Alcohol 2001;36:556-63. 
[108] Noël X, Van der Linden M, Sferrazza R, Schmidt N, De Mol J, Hanak C, Pelc I, Verbanck P. Supervisory attentional system in recently detoxified alcoholic patients. Arch Gen Psychiat 2001;58:1152-8.

[109] Cadete-Leite A, Tavares MA, Uylings HB, Paula-Barbosa M. Granule cell loss and dendritic regrowth in the hippocampal dentate gyrus of the rat after chronic alcohol consumption. Brain Res 1988;473:1-14.

[110] Walker DW, Barnes DE, Zornetzer SF, Hunter BE, Kubanis P. Neuronal loss in hippocampus induced by prolonged ethanol consumption in rats. Science 1980;209:711-3.

[111] Lundqvist C, Alling C, Knoth R, Volk B. Intermittent ethanol exposure of adults rats: hippocampal cell loss after one month of treatment. Alcohol Alcohol 1995;30:737-48.

[112] Lundqvist C, Volk B, Knoth R, Alling C. Long-term effects of intermittent versus continuous ethanol exposure on hippocampal synapses of the rat. Acta Neuropathol 1994;87:242-9.

[113] Franke H, Kittner H, Berger P, Wikner K, Schramek J. The reaction of astrocytes and neurons in the hippocampus of adult rats during chronic ethanol treatment and correlations to behavioral impairments. Alcohol 1997;14:445-54.

[114] Davidson MD, Wilce P, Shanley BC. Increased sensitivity of the hippocampus in ethanol-dependent rats to toxic effect of N-methyl-D-aspartatic acid in vivo. Brain Res 1993;606:5-9.

[115] Sepulveda C, Bustos G, Gysling K, Seguel M, Labarca R. Effect of in vitro ethanol and chronic ethanol consumption on the release of excitatory amino acids in the rat hippocampus. Brain Res 1995;674:104-6.

[116] Elliot EM, Sapolsky RM. Corticosterone enhances kainic acid-induced calcium elevation in cultured hippocampal neurons. J Neurochem 1992;59:1033-40.

[117] Elliot EM, Sapolsky RM. Corticosterone impairs hippocampal neuronal calcium regulation. Possible mediating mechanisms. Brain Res 1993;602:84-90.

[118] McIntosh LJ, Sapolsky RM. Glucocorticoids may enhance oxygen radical-mediated neurotoxicity. Neurotoxicology 1996;17:873-82.

[119] Uno H, Eisele S, Sakai A, Shelton S, Baker E, DeJesus O, Holden J. Neurotoxicity of glucocorticoids in the primate brain. Horm Behav 1994;28:336-48.

[120] Yusim A, Franklin L, Brooke S, Ajilore O, Sapolsky R. Glucocorticoids exacerbate the deleterious effects of gp120 in hippocampal and cortical explants. J Neurochem 2000;74:1000-7.

[121] Koob GF, Mason BJ, De Witte P, Littleton J, Siggins GR. Potential neuroprotective effects of acamprosate. Alcohol Clin Exp Res 2002;26:586-92. 